\title{
Futuro do presente: novos cenários emergem nas experiências midiáticas do cotidiano mediado por telas
}

\author{
Future of the present: new scenarios emerge in everyday media \\ experiences mediated by screens
}

\section{Futuro del presente: emergen nuevos escenarios en las experiencias mediáticas cotidianas mediadas por pantallas}

\section{Adriana BARSOTTI ${ }^{1}$ Cláudia QUADROS² Suzana BARBOSA 3}

A pandemia de Covid-19 provocou rupturas em amplos aspectos de nossa experiência cotidiana: nos modos de produzir e consumir informação, de trabalhar, de aprender e de nos entretermos. De repente, vimos praticamente toda existência ser mediada por telas e as tecnologias ganhando um papel central em nossas vivências, marcando interações sociais e criando novos regimes de sociabilidade. A prevalência do digital e a interferência das telas no cotidiano conformam o digital como um terceiro entorno social, que se integra aos entornos natural e urbano, como proposto por Boczkowski e Michelstein (2021).

Nesse contexto, o processo de plataformização foi notadamente acelerado durante o período. O número de usuários de redes sociais no mundo aumentou 13\% e,

\footnotetext{
${ }^{1}$ Professora do Departamento de Comunicação e do Programa de Pós-Graduação em Mídia e Cotidiano (PPGMC-UFF), ambos da Universidade Federal Fluminense. Jornalista pela Universidade Federal do Rio de Janeiro (UFRJ) e doutora em Comunicação Social pela Pontifícia Universidade Católica do Rio de Janeiro (PUC-Rio). E-mail: barsotti.adriana@gmail.com ORCID: https://orcid.org/oooo-0oo27834-9937

2 Professora do PPGCOM-UFPR. Coordenadora do grupo de Pesquisa COMXXI. Jornalista e relações públicas pela Universidade Federal do Paraná, com doutorado em Comunicação pela Universidade de La Laguna e pós-doutorado em Comunicação pela Universidade Pompeu Fabra. E-mail: clauquadros@gmail.com ORCID: https://orcid.org/oooo-0003-1322-8971

3 Professora do Departamento de Comunicação e do Programa de Pós-Graduação em Comunicação e Cultura Contemporâneas (PósCom), ambos da Universidade Federal da Bahia (FACOM | UFBA). Coordenadora do Grupo de Pesquisa em Jornalismo On-Line (GJOL). É jornalista e doutora em Comunicação pela UFBA, com pós-doutorado pela Universidade de Santiago de Compostela. E-mail: suzana.barbosa@gmail.com. ORCID: https://orcid.org/oooo-0003-3109-7637
} 
no Brasil, as mídias sociais atingiram 70\% de penetração (HOOTSUITE, 2021), número significativo diante da exclusão digital que persiste no país, onde um a cada cinco brasileiros permanece sem acesso à internet (IBGE, 2020). Desorientados e confinados devido ao isolamento social, internautas recorreram desenfreadamente ao Google na busca por informações sobre a Covid-19, levando a empresa a bater recorde de receita com seu mecanismo de busca em 2021 (GOOGLE, 2021).

A expressão "processo de plataformização" foi aqui usada intencionalmente porque refutamos a análise das grandes plataformas de busca, de redes sociais e de streaming enquanto "objetos". Adotamos a perspectiva de Van Dijck, Poell e De Waal (2018) e Poell, Nieborg e Van Dijck (2020) para compreendermos a plataformização como um processo dinâmico, que entrelaça as infraestruturas das plataformas, suas políticas de governança e processos econômicos com diversas esferas da nossa vida cotidiana, gerando a reorganização de práticas culturais. Sob a perspectiva dos estudos culturais, é preciso enxergar as nuances que estão em jogo. De um lado, trata-se de observar a intensificação da dominação do capital transnacional dessas grandes plataformas. De outro, é preciso ficar atento às apropriações e ressignificações que os usuários delas fazem, gerando múltiplos pactos de sociabilidade.

A reboque da expansão das plataformas, a desinformação e o negacionismo se expandiram no contexto da Covid-19, trazendo consequências danosas para a sociedade. Diversos segmentos passaram a refletir sobre esses fenômenos, que também têm afetado diferentes áreas do conhecimento, como a comunicação e a ciência. A aceleração do uso dos algoritmos, da inteligência artificial e do big data, observada nos produtos midiáticos, trouxeram novos desafios práticos e éticos para comunicadores no século XXI. O entretenimento, atravessado e estruturado pelas mídias, também não escapou da aceleração digital: assiste-se à uma multiplicação de plataformas de streaming de áudio e de vídeo, impactando o campo da cultura.

Ainda no século XX, Morin já recomendava que os estudos sobre a comunicação deveriam perpassar o contexto histórico e cultural, "no seu perpétuo movimento da técnica à alma humana, da alma humana à técnica, lançadeira que percorre todo o processo social" (2009, p.21). A premissa deste dossiê é evitar o determinismo tecnológico, como sugere Morin, e também a perspectiva de uma história evolutiva. A pandemia está prestes a completar dois anos e, nesse período, ouvimos algumas vezes que estávamos perto de seu "fim". E eis que a Ômicron surge em dezembro, rompendo com a sonhada narrativa sobre o término da pandemia - ela mesma "pulando" duas 
letras do alfabeto grego, utilizado pela Organização Mundial de Saúde (OMS) desde o início da pandemia para designar as variantes do novo coronavírus. Em vez de começos e fins, mais enriquecedor seria enxergar rupturas e continuidades, como propõe Foucault (2015). E rupturas já podem ser vislumbradas, como demonstram os textos que compõem este dossiê temático.

Novos cenários já começam a emergir nas experiências midiáticas e, muitas delas, devem continuar no período pós-pandemia. Questionamos na chamada deste dossiê quais seriam as rupturas e continuidades que já podem e poderão ser percebidas na produção, consumo, distribuição, circulação e recirculação dos produtos midiáticos. Se a nossa experiência cotidiana é atravessada pelas mídias, qual papel elas desempenharão nesse contexto de intensificação da hibridização entre os espaços físicos e virtuais que já começamos a vislumbrar? Os textos selecionados neste dossiê refletem sobre diferentes mídias no nosso cotidiano no contexto da pandemia, trazendo importantes apontamentos sobre o futuro de cada uma delas e sua relação com a audiência.

O rádio, observado como companheiro do ouvinte por cientistas e profissionais da comunicação, ganha novos sentidos entre pacientes hospitalizados devido à Covid19. Em Amuleto contra o vírus: sentidos da escuta radiofônica entre pacientes hospitalizados, Nilda Jacks revisitou investigações sobre o rádio a partir de uma ação realizada em um hospital de Porto Alegre (RS) para animar pacientes com Covid-19. Os depoimentos sobre o impacto do radinho de pilha entre esses pacientes foram dados por profissionais de saúde para o jornal Zero Hora. A reportagem da jornalista Larissa Roso emocionou e inspirou a pesquisadora, que traz à tona diversos estudos que abordam a relação entre o rádio e o ouvinte. Ao longo do seu ensaio, Nilda Jacks reflete sobre procedimentos metodológicos adotados por alguns estudos e abordagens que evidenciam os sentidos da escuta radiofônica. De forma sensível, Jacks relata a conexão de pacientes com o mundo exterior por meio do rádio. Essa relação não é nova, como bem aponta a pesquisadora, mas o contexto da pandemia revelou novas possibilidades para se pensar o rádio e as pesquisas futuras sobre o meio.

Os dois textos seguintes - O corpo performático nas redes sociais: narrativas audiovisuais no reels do Instagram e A "Morada" como constelação e encruzilhada: estética e política em experiências audiovisuais - também trazem olhares que se debruçam sobre o acolhimento e a identificação gerada por produtos midiáticos durante a pandemia e cujas perspectivas promissoras devem permanecer no cenário 
pós-pandêmico. Renata Pitombo Cidreira e Naiara Moura Pinto analisaram vídeos de quatro influenciadoras digitais "dissidentes" publicados na ferramenta reels, do Instagram. Para as autoras, os corpos performáticos e dissonantes observados - corpo idoso, negro, obeso e deficiente - são meios de partilha de significados e interpelam seus espectadores nas pautas assertivas sobre o empoderamento feminino por meio da única presença possível na pandemia: a copresença virtual.

Em A "Morada" como constelação e encruzilhada: estética e política em experiências audiovisuais, Scheilla Franca de Souza e Jorge Cardoso Filho estabelecem uma constelação de experiências audiovisuais de coletivos e lives nas redes sociais que são marcadas pelo signo da morada e produzidas sob as óticas amefricanas e ameríndias. Na pandemia, quando foi necessário o recolhimento às casas, os autores questionam: quais as relações que se estabelecem entre intimidade e comunidade, entre vida cotidiana e ficção? O plano pandêmico, em sua domesticidade, indica a abertura para a alteridade, por meio das relações entre os sujeitos, os afetos, o comum, o partilhado. O reconhecimento dessas outras possibilidades abre caminho para experiências estéticas futuras, pois, pontuam os autores, "o agora porvir está em devir".

E quais são as possibilidades de construção de novos territórios para o jornalismo, em meio ao cenário de desinformação? No Brasil, pela primeira vez, o consumo de notícias pelas redes sociais superou o da TV aberta durante a pandemia, como demonstraram os relatórios do Digital News Report, produzidos pelo Reuters Institute for the Study of Journalism em parceria com a Universidade de Oxford (2021, 2020). Paradoxalmente, os brasileiros são os que mais se preocupam com a desinformação, de acordo com a mesma pesquisa, sinalizando que há possibilidades para o jornalismo. Em O Maranhão pelo jornalismo efêmero dos Stories: a construção de territórios em O Imparcial, Imirante e Imperatriz Online, Petronilio Ferreira, Paula Melani Rocha e Rafael Schoenherr indicam que a produção desses veículos jornalísticos para os Stories tem características jornalísticas e carrega potencialmente novas formas de transmissão de notícia após o período pandêmico.

Os últimos dois textos refletem sobre o futuro do entretenimento, apontando para um caminho de rupturas em meio a continuidades. Em Masterplano: mediação radical em ambientes de festas online no contexto da pandemia, Natália Moura Pacheco Cortez e Sóstenes Reis Siqueira observaram a migração do coletivo artístico mineiro Masterplano para a cena virtual. As festas - antítese do isolamento social - 
ganham novas configurações nas plataformas digitais, permitindo a emergência de outros espaços e temporalidades para as comunidades que antes só festejavam em espaços físicos.

O Brasil definitivamente não é um país de leitores. A pesquisa Retratos da Leitura no Brasil (2019), do Instituto Pró-livro (IPL), demonstra que 50\% da população brasileira não lê livros. Mas será que o isolamento social da pandemia não mudou os hábitos de leitura de brasileiros? A pesquisa feita por Marília de Araújo Barcellos faz um registro deste cenário. No artigo Leitura e consumo de livros, no Brasil, em tempos de Covid-19, a autora compara indicadores de leitura de antes e durante a pandemia com os resultados encontrados em sua pesquisa com estudantes universitários da Universidade Federal de Santa Maria (UFSM) e a relação deles com livros impressos, e-books e audiobooks. Entre os universitários, ela concluiu que houve uma disruptura no hábito de consumo de livros. A autora registrou o aumento do letramento digital dos discentes e a inclusão da leitura de entretenimento como hábito, concorrendo com outras tantas possibilidades de lazer.

E é com uma discussão sobre masculinidade em mulheres e lesbianidade a partir de um produto do campo do entretenimento cultural - a minissérie televisiva Amor na Ponta da Língua (2002) que iniciamos a Seção Livre. O artigo de Daniela Conegatti resgata o conceito de anômalo (DELEUZE \& GUATTARI, 1997) e a teoria performativa (BUTLER, 2013), de modo a possibilitar uma discussão sobre a resistência à abjeção e emergência do anômalo, tendo como horizonte o conceito nomeado pela autora de “devir-sapatão”. Mantendo o foco na mulher, o segundo artigo dessa Seção, Mulheres curdas sob a perspectiva cinematográfica: uma discussão sobre o filme Filhas do Sol, de Jamer Guterres de Mello, Juliana Santoros Miranda e Maria Ignês Carlos Magno, traz uma discussão sobre a obra audiovisual dirigida pela cineasta Eva Husson, propondo, entre outras questões, a oposição Ocidente/Oriente em relação à representatividade feminina.

Já no texto seguinte, Corpo feminino, envelhecimento e Indústria Cultural: uma análise de propaganda à luz da Teoria Crítica, Viviane Visanti e Marsiel Pacífico abordam o feminino de uma perspectiva etária, ao analisarem a peça publicitária de um cosmético para rejuvenescimento. Com um enquadramento crítico, os autores propõem uma reflexão sobre as tensões existentes nos discursos midiáticos sobre envelhecimento. Quanto ao artigo Hábitos imagéticos dos jovens: o auge dos stories e a inexpressividade das narrativas em 360 graus, o quarto da seção, os autores Alan 
Angeluci e Carolina Falandes deslocam a discussão para a juventude, apresentando os dados de um survey com 290 estudantes, cujo objetivo foi compreender a relação de estudantes do ensino médio e superior com a produção e o consumo de imagens em ambientes digitais. Também com foco no grupo etário juvenil, Clarice Greco e Enoe Pontes assinam Disputas de sentido em comunidades de fãs: amor e ódio entre Riverdalians. O texto oferece uma análise qualitativa das postagens do fandom brasileiro de uma série estadunidense e revela que, embora unidos por afetos comuns, os fãs desenvolvem chaves interpretativas distintas, as quais manifestam disputas de sentido.

De certo modo também trabalhando nesse território de embates de sentidos Reflexões sobre Jornalismo Literário e cotidiano, de Mônica Martinez, recupera parte da travessia da construção conceitual dos estudos que têm se debruçado sobre a relação entre jornalismo e literatura. A perspectiva é tanto problematizar o acontecimento quanto discutir as marcas da subjetividade na fabulação das narrativas. Traz, deste modo, uma contribuição significativa para este tema que sempre mobiliza o campo. E, fechando a Seção Livre, temos Meios de Comunicação, Alienação e Extensão: a inocência no uso dos novos meios de comunicação, de Patrício Dugnani. O artigo busca tensionar, dialeticamente, as teorias críticas e a dos meios, procurando elaborar uma síntese que se assenta na recuperação da história dos meios de comunicação de massa, o nazismo e os meios digitais. Com este percurso, nós, editoras do dossiê e da seção livre, desejamos uma boa leitura. Os artigos selecionados trazem diferentes perspectivas da comunicação durante o período pandêmico e lançam frestas para enxergarmos rupturas e continuidades em um futuro que já é presente no nosso cotidiano em construção.

Adriana Barsotti, Cláudia Quadros, Suzana Barbosa (Ed. Seção Temática) Denise Tavares, Larissa Morais e Renata Tomaz (Ed. da Seção Livre)

\section{Referências}

BOCZKOWSKI, P.; MICHELSTEIN, E. The digital environment: How we live, learn, work, and play now. Cambridge, MA: MIT Press, 2021.

BUTLER, Judith. Problemas de gênero. Feminismo e subversão da identidade. Rio de Janeiro: Civilização brasileira, 2013. 
DELEUZE, Gilles; GUATTARI, Felix. Mil platôs - capitalismo e esquizofrenia - vol. 4. Suely Rolnik (trad.) São Paulo: Ed. 34, 1997.

FOUCAULT, Michel. Arqueologia do saber. Rio de Janeiro: Forense Universitária, 2015.

GOOGLE Search, YouTube sales soar to record high in Covid-19 pandemic. Business Standard, San Francisco, 28 jul. 2021. Disponível em <https://www.businessstandard.com/article/international/google-search-youtube-sales-soar-to-record-high-incovid-19-pandemic-121072800307_1.html>. Acesso em 13 jan. 2022.

HOOTSUITE. We are social. Nova York, 2021. Disponível em <https://wearesocial.com/digital-2021>. Acesso em 13 jan. de 2022.

IBGE. Pnad Contínua-TIC. Rio de Janeiro, 2020. Disponível em <https://biblioteca.ibge.gov.br/index.php/biblioteca-catalogo?view=detalhes\&id=2101705>. Acesso em 13 jan. 2022.

INSTITUTO PRÓ-LIVRO. Retratos da leitura no Brasil. São Paulo, 2019.

MORIN, Edgar. Cultura de massas no século XX: neurose. Rio de Janeiro: Forense Universitária, 2009.

NEWMAN, Nic; FLETCHER, Richard; SCHULZ, Anne; ANDI, Simge; ROBERTSON, Craig; NIELSEN, Rasmus Kleis. Reuters Institute Digital News Report 2021. Reuters Institute for the Study of Journalism, 2021. Disponível em: <https://reutersinstitute.politics.ox.ac.uk/digital-news-report/2021> Acesso em: 20 set. 2021.

NEWMAN, Nic; FLETCHER, Richard; SCHULZ, Anne; ANDI, Simge; ROBERTSON, Craig; NIELSEN, Rasmus Kleis. Digital News Report 2020. Oxford, 2020. Disponível em <https://www.digitalnewsreport.org/survey/2020/>. Acesso em 13 jan. 2022.

POELL, Thomas; NIEBORG, David; VAN DIJCK, José. Plataformização. Revista Fronteiras - estudos midiáticos. São Leopoldo, v.22, n.1, p. 2-10, 2020.

VAN DIJCK, José; POELL, Thomas; WAAL, Martijn. The platform society. Public values in a connective world. New York: Oxford University Press, 2018. 